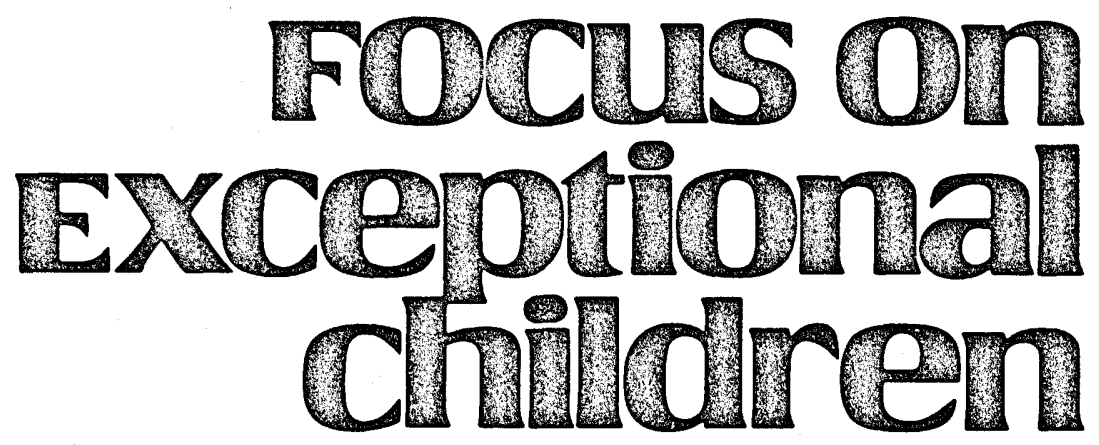

\title{
The Foxfire Pedagogy: A Confluence of Best Practices for Special Education
}

\author{
E. Eugene Ensminger and Harry L. Dangel
}

Recent follow-up studies of students with learning disabilities as well as others with mild disabilities (behavior disorders and mild mental retardation) provide evidence that instructional programs designed for these populations have been less than effective. Several studies have reported high dropout rates for students with mild disabilities (Edgar, 1987; Hasazi, Gordon, \& Roe, 1985; Hasazi, Gordon, Roe, Hull, Finck, \& Salembier, 1985; Wolman, Bruininks, \& Thurlow, 1989; Zigmond \& Thornton, 1985). The dropout studies reviewed by Wolman et al. (1989) report dropout rates for students with mild handicaps as high as $50 \%$, and in most cases the percentage is approximately twice the rate of nondisabled comparison groups.

Edgar's (1987) study of the post-school status of students in mildly handicapped programs in Washington state and his call for rethinking the educational programs for this population have provided a stimulus for curriculum reform. Whether they graduated or dropped out, most of the students previously enrolled in special education programs were receiving less than minimum wage. If the goal is a successful transition from secondary schools to post-secondary training or the world of work, the outlook, based on these results, is not promising with the present curriculum focus and instructional delivery designs. Edgar (1987) and Zigmond (1990) both have expressed the belief that the high dropout rates and the lack of post-school success for students classified as mildly disabled provide indirect evidence of the ineffectiveness of special education and call for rethinking the curriculum, especially for services offered at the secondary level. The need for curriculum and instructional reform in special education has focused largely on the secondary level (Affleck, Edgar, Levine, \& Kostering, 1990; Halpern \& Benz, 1987; Millward, 1987; Polloway, Patton, Epstein, \& Smith, 1989; Wolman, Bruininks, \& Thurlow, 1989; Zigmond, 1990). Recently, Polloway, Patton, Smith, \& Roderique (1991) have recommended that curriculum and instructional reform occur, as well, at the elementary level for students with mild mental retardation.

The curriculum and instructional reform recommendations range from rethinking curriculum content to restructuring the way in which instruction is delivered (Polloway et al. 1989; Zigmond, 1990). Clough (1988) and Millward (1987), in Great Britain, advocate rethinking curriculum development for the "low attainer" and call for an integrated, experiential approach to instruction for the "special needs" student.

Gene Ensminger is Professor and Coordinator, Undergraduate Program, Department of Special Education, Georgia State University, where Harry Dangel is Associate Professor and Coordinator, Learning Disabilities Program, Department of Special Education. 
Although many factors contribute to the relatively poor school outcome for students with mild disabilities, this article addresses the student perspective of schooling, current instructional practices that thwart student motivation for learning, and emerging practices that potentially make learning more connected and purposeful for students with mild disabilities. The Foxfire approach to instruction described here incorporates the recommended practices of holistic thought, cooperative learning, and student self-determination in the instructional process.

\section{PRESENT LEARNING ENVIRONMENTS}

Schools and classrooms in the United States are reported to be unexciting for regular (Goodlad, 1984; Sizer, 1984) and special (Ensminger, 1991; Steinberg, 1991) education students. Goodlad, in A Place Called School: Prospects for the Future, and Sizer, in Horace's Compromise: The Dilemma of the American High School, provide a disconcerting view of America's schools. The general themes that emerge from these observational studies is that schools don't know what they are about, students are forced to be there, stu-

\section{FOcus on Exceptional children}

ISSN 0015-511X FOCUS ON EXCEPTIONAL CHILDREN (USPS 203-360) is published monthly except June, July, and August as a service to teachers, special educators, curriculum specialists, administrators, and those concerned with the special education of exceptional children. This publication is annotated and indexed by the ERIC Clearinghouse on Handicapped and Gifted Children for publication in the monthly Current Index to Journals in Education (CIJE) and the quarterly index, Exceptional Children Education Resources (ECER). It is also available in microfilm from Xerox University Microfilms, Ann Arbor, MI. Subscription rates: Individual, \$27 per year; institutions, $\$ 36$ per year. Copyright (C) 1992, Love Publishing Company. All rights reserved. Reproduction in whole or part without written permission is prohibited. Printed in the United States of America. Second class postage is paid at Denver, Colorado. POSTMASTER: Send address changes to:

$$
\begin{aligned}
& \text { Love Publishing Company } \\
& \text { Executive and Editorial Office } \\
& 1777 \text { South Bellaire Street } \\
& \text { Denver, Colorado } 80222 \\
& \text { Telephone (303) 757-2579 }
\end{aligned}
$$

Edward L. Meyen University of Kansas Glenn A. Vergason
Georgia State University

Richard J. Whelan

University of Kansas Medical Center

Stanley F. Love Publisher
Holly T. Rumpler Senior Editor dents and teachers don't have much control over what is to go on in the classroom (helplessness), the schools do not have a clear purpose agreed upon by various elements of society (home, community, church, business, technology), and lack an environment that enhances motivation for learning by relating instruction to "realworld" experiences.

In recent observations of special education classes, many of the themes are consistent with those identified by Goodlad and Sizer (Ensminger, 1991; Steinberg, 1991). In an attempt to understand the educational environment provided students with learning disabilities, Ensminger visited students and teachers in 10 high schools in five school districts in the Atlanta, Georgia, metropolitan area. Most of the students were attending resource classes for students identified as mildly disabled (behavior disorders, learning disabilities, and mild mental retardation). Typically, students were assigned individual work that corresponded with courses they were taking in the mainstream classes or they were completing a required Carnegie course within the confines of the resource room. The format for instruction was a textbook or worksheets, or both. Rarely were students conversing about the material with other students or the teacher. The environment, in most instances, could be described as a "study hall," with independent assignments and limited verbal exchanges.

Whenever students were invited to share their attitudes and beliefs about school and their perceived benefits of the special program, the vast majority of their responses indicated dissatisfaction. The most frequent comment students made was "school is boring." They were not excited about being in school or with the focus of instruction. They reported not seeing any connection between what was being taught and how it applied to their lives. They did not enjoy working alone on assignments and preferred having opportunities to discuss what they were studying with other students.

Similarly, Steinberg (1991) observed that students in classes for behavior disordered students were not permitted to talk with classmates, as school authorities believed this would lead to disruption. Ensminger concluded, "I had anticipated from the outset that neither students nor teachers were going to be terribly enthusiastic about what was going on, but I had no idea that the general climate in the secondary programs was as negative as I found it" (p. 46). Students with mild disabilities seem to have perceptions of schooling similar to those of the regular education population (Goodlad, 1984; Sizer, 1984).

In general, students served as mildly disabled are bored with school, they find little relevance of instruction to their everyday lives, and they desire more opportunity for cooperatively sharing with others in the learning experience. In our opinion, the present skill remediation and tutorial emphasis of instruction, frequently practiced in special education programs for students with mild disabilities, seems to promote amotivated students. 


\section{Current Instructional Practices}

Special education, and particularly the field of learning disabilities, has been dominated by orientations that center on reducing the learning deficits of students to hypothetical constructs. These constructs are further used as explanations for the learning deficiencies. These reductionistic orientations place major emphasis on viewing the learner as the primary source of the dysfunctional learning, and the resulting instructional approach has been to bolster the learner's performance by concentrating on improving the deficit(s) identified (see Poplin, 1988b, for an excellent review of the issues surrounding reductionistic approaches to learning disabilities). The dominant instructional approach, then, has been to focus on students' disabilities rather than abilities. Our expectations of the learner have been determined by our documented limitations of the learner, and instruction tends to follow a "fix-it" orientation. The result is instruction that concentrates on specific skills or processes devoid of content and meaningful connection to relevant experiences and interests of students. The missing ingredient in instruction is the “. . . organic connection between education and personal experience" (Dewey, 1963, p. 25).

\section{A Shift in Orientation}

The educational approach to teaching students with learning disabilities (and other students with mild disabilities). is shifting to a more holistic/constructivist or cognitive approach that emphasizes the importance of connecting learning to student experience (Poplin, 1988a; Reid, 1988; Reid \& Stone, 1991; Polloway, Patton, Smith, \& Roderique, 1991). In addition is recognition of the need for empowering students by involving them in planning and executing instruction (Adelman \& Taylor, 1986, 1990; Cohen, 1986; Deci \& Chandler, 1986; Switzky \& Schultz, 1988), and the importance of making learning a more cooperative experience (Hilke, 1990; Johnson \& Johnson, 1983; Lloyd, Crowley, Kohler, \& Strain, 1988; Sharan \& Hertz-Lazarowitz, 1980).

\section{The Holistic/Constructivist Approach}

The holistic/constructivist orientation recognizes that learning is dependent on prior learning experiences. Of great importance to holistic or experiential learning is that skill and process instruction is integrated with information that matches the student's desires, interests, and experiences (Dewey, 1963; Poplin, 1988a). Instruction that incorporates holistic practices commonly uses thematic units or projects. The integrated experience unit or project approach to instruction is not new to the field of special education. In 1935, Ingram espoused the experience unit approach for working with slow learners. Her orientation was greatly influenced by Dewey's philosophy. Kirk and Johnson (1951) summarized Ingram's criteria for effective units of work as follows:
1) The units of work should evolve from real life situations of the children and grow out of the direct interest of the children.

2) The choice of unit should depend on the child's level of development in mental, social, and physical activities.

3) The unit should develop the individual as an individual and should further group activities in participation and co-operation.

4) The unit selected should be one that develops interest of basic habits and attitudes. These should include knowledges and skills necessary in social participation.

5) The unit selected should be one that develops interest in out-of school activities. A unit that goes beyond the classroom participation into the home and community would be superior to a unit that exits only in the classroom.

6) The unit selected should include activities which utilize the tool subjects. Teaching reading, writing, and arithmetic should be correlated with the unit whenever possible.

7) The unit should be of such a nature that it provides children with a variety of experiences. (pp. 93-94)

Others have echoed the importance of the role of prior student experience in instructional planning. In his classic volume entitled Teaching the Slow Learner, Featherstone (1951) made the following observation about the nature of experience:

The content of these experiences, that is, the subject matter, must possess characteristics which enable the pupil to tie it into past experience readily; otherwise he will be unable to "respond with meaning" to ideas he encounters in books, or to any life situation he encounters for the first time. (p. 42)

More recently, Meyen (1981) has advocated instructional units as the mechanism for organizing instruction for regular and special education students alike. He has noted that for students with deficient academic skills, the integrated experience unit is highly desirable.

The primary learner characteristics that make [integrated experience] units highly desirable relate to the capabilities of embedding the teaching of skills, concepts, and information in experiences highly meaningful to the learner. (p. 6)

Whatever one prefers to call it-holistic, experiential, or cognitive instruction-the emphasis is on relating the learning of skill, knowledge, and attitudes to something meaningful in the student's life. The principles of instruction espoused by Ingram (1935), Featherstone (1951), and Meyen (1981) serve as an historical reminder of the importance of the experiential learning pedagogy for students with mild disabilities.

\section{Human Motivation Theory}

As Deci and Chandler (1986) have observed, motivation involves self-determination, competence, and relatedness. Students need to have some role in the decision-making process, to have some say about what they are studying and how they can best study it. 
Self-determination as a quality of behavior should be a goal of all education. ... We would like the education of all children, including LD and other special population children, to be organized by the principles that promote self-determined functioning. Such functioning would capitalize on the intrinsically motivated behavior-behavior that is organized by interest and the desire to take on new challenges-and it would also facilitate the internalization and eventual integration of external regulations that are necessary for effective functioning in the social world. (p. 589)

Students with learning disabilities, after a history of school failure, frequently develop attitudes of "helplessness" (Smith, 1990). The typical strategy is to provide extrinsic rewards to maintain task orientation (completion), which quite likely enhances dependence on others to promote engagement in learning tasks (Deci \& Chandler, 1986). The student usually is not given options for either the content to be studied or the opportunity to explore strategies for learning. With a limited opportunity to engage in the learning process at the decision-making level, it is not surprising that students develop a "don't care" attitude toward school and the learning process. Even when the decision is made about placement in special education programs, the student's opinion, feelings, and preferences are not usually explored. With the student being left out of the decision-making process, ownership and responsibility for learning is greatly reduced.

\section{Cooperative Learning}

The vast majority of students engage in an instructional activity without knowing its purpose, or how what they have been assigned connects with anything in their lives, and without an opportunity for self-assessment of what might be the best way to proceed with the task assigned. Self-determination is omitted from the instructional process. It does not offer students some choice of topics to study to which their learning objectives can be tied. In the absence of meaningful content that relates to student experience and interest, skill instruction is devoid of association with application. Objectives of the "basics" should be integrated with content that is useful to the student's present life experience and needs, and the student should engage in purposeful activities decided upon jointly by other classmates and the teacher. To further the process of involvement, the student needs to share the responsibility of accomplishing learning experiences with other classmates, thus advancing the opportunity to learn from each other. A byproduct of this cooperative learning is the socialization process it fosters.

Cooperative learning involves groups of students working together, in a common effort, to assist each other in completing a learning task or project. The various cooperative learning methods have a central purpose: to facilitate individual accomplishment by having the group members assume responsibility for each other's success (Slavin, 1990). Studies of the benefits of cooperative learning have demonstrated that students engaged with others in the learning process certainly develop more positive feelings about themselves, learn to interact in social situations, and in many instances show improved achievement (Hilke, 1990; Lloyd et al., 1988). In the study of students with and without handicaps, the cooperative learning approach was found superior to the competitive or individualistic approach (Johnson \& Johnson, 1983).

Although we will not debate the mainstream versus resource delivery system here, we do point out that students learn from others who have previously mastered certain skills as well as how they approach solving particular learning tasks. To acquire new skills and knowledge, most students must have an "expert" to show them the ropes. Within any grouping of individuals with learning disabilities are students who have acquired skills and knowledge that other students have not. The cooperative approach also provides moral support to group members that enhances exploration and discovery, enhancing the motivation to maintain task orientation.

\section{The Experiential Education Movement}

The confluence of orientations of the holistic/constructivist theory, human motivation theory, and cooperative learning represents three of the key components in the experiential education movement. The student's prior experience and knowledge provide the base from which subsequent learning emanates. Learning is elaborated from past instances of knowing and gracefully spirals into new knowledge and the modification of previous understandings (Dewey, 1963; Poplin, 1988a). Having the opportunity to develop one's own approach to learning by making recommendations for topics or content that reflects the interests and desires of the individuals within a group promotes ownership and responsibility for performing and achieving, thus promoting self-determination (Deci \& Chandler, 1986).

Learning processes are further elaborated by students working together for a common purpose, jointly sharing the process, the negotiation, and the final product of that learning relationship (Sharan \& Lazarowitz, 1980). The ever-present fear of teachers is that permitting students to work together increases the risk of misbehavior. But, when students are permitted to have a role in setting the behavior standards, to determine the content to achieve the prescribed objectives, and to arrive at procedures for demonstrating mastery of learning, student misbehavior is greatly reduced (see Adelman \& Taylor, 1990, for a review of the issues surrounding school misbehavior and the implications for intrinsic motivation in the intervention process).

\section{THE FOXFIRE APPROACH}

The components of holism, self-determination, and cooperative learning are fundamental tenets of the Foxfire approach to learning. Foxfire is an experiential approach designed to empower students 
and teachers in the learning process. Although it was initially developed for nonhandicapped Appalachian students, it incorporates the elements of best practices emerging in the education of students with mild disabilities.

The word Foxfire in the educational and lay communities is most commonly associated with a series of publications known as the Foxfire Books. This series (nine Foxfire books were published by Doubleday between 1972 and 1986) represents a compilation of student articles that either appeared in the Foxfire magazine or were prepared especially for publication in the various Foxfire books. The Foxfire books became best sellers as readers were fascinated by the customs, practices, and lore of the Appalachian Mountain people. The underlying pedagogy of instruction went essentially unnoticed.

In 1966, Eliot Wigginton became a high school teacher of English in a small private school in North Georgia. The students attending this school were a mix of those living in residence and, through an agreement with the Rabun County Board of Education, those living in the community. As a new teacher, Wigginton experienced students' apathy toward the traditional academic agenda and quickly recognized the need to involve them in determining the direction of the class and how the students and teacher were together going to achieve the objectives of the English class. Wigginton's account of the trials of getting students interested in learning, his growing understanding of the principles that guide student involvement in the learning process, and the administrative roadblocks to implementation of what is now referred to as the Foxfire approach to teaching, are documented in his award-winning book, Sometimes a Shining Moment: The Foxfire Experience (Wigginton, 1985).

Now, 25 years later, Wigginton (1989) continues to employ the pedagogy in his own classroom and, through the Foxfire Teacher Outreach Center, is expanding the application of the Foxfire pedagogy in classrooms across the United States (see the Appendix for locations of network centers). The Foxfire pedagogy has evolved into a set of core practices and procedures being used with all ages of students (including English as a second language classes at the college level) and with special education students (with moderate retardation, learning disabilities, and behavior disorders). (See Smith, 1989, for a description of classroom projects that teachers have developed as a result of the Foxfire courses offered through the Network Centers.)

\section{Foxfire Core Practices}

The core practices guide implementation of the Foxfire experiential approach to learning. These are not viewed as "scriptural" but, rather, as points to make learning meaningful, effective, and empowering for students (Wigginton \& Smith, 1990). The ultimate goal is to have

... students become more thoughtful participants in their own education, [and] our goal must be to help them become increasingly able and willing to guide their own learning, fearlessly, for the rest of their lives. Through constant evaluation of experience, and examination and application of the curriculum, they approach a state of independence, of responsible behavior, and even, in the best of all worlds, of something called wisdom. (p. 9)

Although these core practices are continuing to be reevaluated and revised, 11 practices currently highlight the intent of instruction guided by the Foxfire approach. The central element of the Foxfire pedagogy is that students are involved in decision making. Unlike traditional classrooms in which the teacher directs the work students are to do, in the Foxfire classroom students and teachers work together to determine the focus of instruction. In all instances the students and teacher determine the project or unit of study, plan the steps to achieve the project, connect the required learning objectives to the experience, design procedures for evaluating their work, and target the project for an interested audience.

\section{Core practice 1: All the work teachers and students do together must flow from student desire, student concerns.}

The interests, desires, and concerns of students ground the learning in experiences that are familiar and important to their lives. This practice is supported by the holistic view that "learners learn best from experiences about which they are passionately interested and are involved" (Poplin, 1988a, p. 405). Not only are student interests and the present context of their world brought to consciousness, but they also are encouraged to act upon these interests by democratically deciding upon, as a group, the work they will do together.

\section{Core practice 2: The role of the teacher must be that of collabora- tor and team leader and guide rather than boss.}

Giving the students the opportunity to have a voice in determining the area of focus and voting upon the choice of a project promotes ownership and, consequently, motivation for student action (Deci \& Chandler, 1986). The teacher's role is to guide, to monitor the activities the students decide to engage in, to raise questions, to point out potential problems, to seek clarification, to become a partner in the learning process, and to assist students in meeting the required objectives of the curriculum.

\section{Core practice 3: The academic integrity of the work must be abso- lutely clear.}

A constant ingredient in the Foxfire approach is the academic agenda or curriculum objectives specified by the state, the school system and, in the case of special education students, the students' individualized education plans (IEPs). Students need to be informed of the curriculum objectives that must be achieved in their assigned program of study, whether in the special program or in the mainstream class. In addition to being informed of the objectives to be 
achieved, they are invited to connect these objectives to whatever project they are doing. Rather than teaching objectives as isolated and fragmented skills, objectives are integrated with information and experiences relevant to students' lives.

In the Foxfire approach students are given the opportunity to review the learning objectives specified for the specific subject or course of study. These objectives are typically posted in the room on a large chart (done by the students or the teacher). After selecting a project for the group to initiate, the objectives are reviewed to determine the objectives that will be covered in the project. The students then identify how they will demonstrate that they have achieved the objective through the project.

Special education teachers include the IEP objectives as a part of this process. Students become partners in planning their achievement of these state, local, and IEP objectives. This fosters the connection of what must be learned to the students' present knowledge and experience. A criticism of special education instruction has been the isolated manner in which objectives have been taught (McGill-Franzen \& Allington, 1991; Poplin, 1984). The Foxfire approach permits students to use their present background of knowledge to discuss these objectives in the physical and social context in which they exist for the students-as something more than abstract statements (Reid \& Stone, 1991).

\section{Core practice 4: The work is characterized by student action rather than passive receipt of processed information.}

The population of students with learning disabilities has been characterized as passive learners (Torgesen, 1977), and students with mild mental retardation frequently fail to develop strategies for organizing and categorizing what is to be learned (Cegelka \& Prehm, 1982). In the absence of action or choice, the traditional interventions of teachers' simply assigning worksheets, drill, and nonmeaningful repetition of isolated, basic skill instruction probably promotes this behavior of nonactive involvement (McGill-Franzen \& Allington, 1991). The Foxfire approach is characterized by active participation in the learning process. Students engage in planning and developing a chosen project, analyze the project and determine tasks to be accomplished, and assist each other in executing the project.

\section{Core practice 5: A constant feature of the process is its emphasis on peer teaching, small-group work, and teamwork.}

During the entire process, students determine what is working and what is not working. They assist each other through peer teaching when a student needs help in acquiring an essential skill or task. Jones (1991), a teacher of an elementary interrelated resource program, had a class of first- through fifth-grade students choose to create a school store. The students surveyed the student body for items they typically needed, researched the best purchase prices for the items, negotiated with the school principal for permission to operate the store and for a location, set up the bookkeeping procedures, set the time schedule for operating the store, determined who would operate the store on different days, and so on. In the process of operating the store, student responsibility changed from time to time, allowing students to learn different aspects of the operation. On one occasion, an older, more able student forgot how to list the daily receipts into the ledger. A first-grade girl with an IQ of 65 quickly responded that she remembered how to do it and proceeded to guide the older student through the process. Jones quickly realized that the labels and the numbers we sometimes use to set expectations are meaningless.

Students using this experiential, active-participant approach to learning can demonstrate their strengths and gain great pride in being involved in a cooperative enterprise. The teacher is not viewed as the primary source of knowledge, and the teamwork provides an excellent opportunity for students to assist each other in acquiring or relearning skills and knowledge.

Core practice 6: Connections between the classroom work and surrounding communities and the real world outside the classroom are clear.

The activities in which students engage should always be connected to the real-world of the community in which the student resides. The context of home, school, and other components of the community provide the context from which learning can occur. As Poplin (1988a) has noted, "What students will learn next is what they already know and what interests them." The connection of real-world events, situations, and activities is what gives us the structure on which to attach new knowledge and to relate academic and social skills, because in the absence of such connections, knowledge and skills are meaningless. The connection of classroom work to real-world practice gives meaning to what otherwise might be viewed as irrelevant, nonuseful information.

\section{Core practice 7: There must be an audience beyond the teacher for student work.}

Foxfire teachers remain constantly vigilant to the need for students to identify an audience for their work. This may be other students, parents, community leaders-some significant others with whom to share. The chosen audience they seek to impress provides a focus for the project they have set out to complete. The importance of the audience goes beyond an opportunity for students to share what has been accomplished; it also provides an opportunity for students to have their work recognized as being significant and important.

An example of the role of an audience for a project is demonstrated by a primary class of students with learning disabilities, taught by Rice (personal communication, April 25, 1991). The stu- 
dents decided they wanted to plan a dinner party for their parents. For several weeks the students developed menus, visited a grocery store to determine costs of various ingredients, identified the roles played by different personnel in the grocery store, wrote reports of their visits, calculated the cost of the food and supplies they would need for their dinner party, and practiced preparing and serving the food. In addition they planned entertainment and a summary report of the process they went through in planning for the dinner party.

For this group of students, the parents provided a purpose for all the work they were doing together and an opportunity to share what they had learned in the process of planning and preparing the meal, and in providing entertainment that demonstrated the new academic skills and knowledge they had acquired. The students discovered from parental reaction that the work they did together was appreciated and that the effort they had put into this activity was worthwhile. This activity provided them with the opportunity to learn new words, to write, to compute, to practice social skills, and to connect their newly acquired knowledge and skills to the real-world of life. Students were no longer failures, but successful learners. They took on a challenge and came out winners.

Core practice 8: As the year progresses, new activities should spiral gracefully out of the old, incorporating lessons learned from past experience, building on skills and understandings that can now be amplified.

As new knowledge and skills are acquired, new questions evolve, and the newly acquired skills allow students to venture into other areas of interest. The conclusion of a project is to be viewed as the starting point for a new project or topic of study. It is a time to take stock of what has been accomplished, what students can do now that they couldn't do before they started the project, and how they can use what they have learned and the new skills acquired to do something new, different, and more difficult than what they have just completed. It is an opportunity to use the recent experience as a time to self-assess their current competencies and to build new connections from past learning to the achievement of additional objectives and newly developed interests.

Core practice 9: As teachers, we must acknowledge the worth of aesthetic experience, model that attitude in our interactions with students, and resist the momentum of policies and practices that deprive students of the chance to use their imaginations.

The learning climate must be conducive to promoting exploration and discovery. The teacher has to gain students' respect by promoting trust and exhibiting a positive regard for students as capable learners (Dewey, 1963; Poplin, 1988a). Teachers need to demonstrate their appreciation of student contributions, acknowledge newly discovered skills and knowledge students demonstrate, and, along with students, celebrate the work of each student. The caution implied by this core practice is that too frequently the recognition of student accomplishment is omitted in the daily routine and pressure of the moment to move on to other activities and experiences. In the rush to cover a specified set of objectives, teachers may fail to take the time to allow students to complete work that is aesthetically satisfying or to allow them to develop more creative and ingenious ways to complete activities.

Core practice 10: Reflection-some conscious, thoughtful time to stand apart from the work itself-is an essential activity that must take place at key points throughout the work.

Both during and at the conclusion of a project, students are encouraged to reflect on the experience. This is a time when students and teacher look back over what has been accomplished and ask themselves: What went well? What would they do differently? What changes should be made in the way we organize ourselves for accomplishing the necessary tasks? This reflection allows students to cooperatively assess the effectiveness of what they have been doing together and to determine what they have learned from their interactions in this shared experience. What new skills and knowledge have they acquired? This is a constant process that keeps students reflecting on the purpose of schooling and the content of the subject matter studied. Based upon reflection of the worth of what has been accomplished and the knowledge gained in the project, students move on to new activities and projects.

Core practice 11: The work must include unstintingly honest, ongoing evaluation for skills and content, and changes in student attitude.

Evaluation of student progress in skills, knowledge, and attitudes must be regularly monitored and "unstintingly honest." As noted, students are made aware of the instructional objectives by identifying the objectives that the chosen project can meet. In addition, students are to identify how they will demonstrate that they have achieved the objectives. In some instances, teachers may develop checklists of specific skills to be acquired and regularly (weekly) record whether the student has demonstrated the skills specified. This student record of accomplishment is kept in a folder that the student retains, providing a ready reference for student self-assessment of progress. In addition, teachers may keep a journal describing student progress, special accomplishments, and general orientation to the work the students are doing.

The core practices represent a merger of many of the best practices proposed for students with learning problems. These practices promote self-determination by having students make decisions about what they would like to study together, in the planning and execution of the chosen project, and in the process of evaluation. 
The principles of cooperative learning, especially the method of group investigation proposed by Sharan and Hertz-Lazarowitz (1980), are an integral part of the Foxfire core practices. The core practices emphasize the importance of holistic/constructivist thought by focusing instruction on the learner's experiential background and constructing connections from those experiences to the prescribed objectives, thus bringing meaning and purpose to those objectives (Poplin, 1988a). The interactive nature of the process places a special emphasis upon shared learning and shared responsibility for academic growth and makes learning a social experience that students can enjoy.

\section{The Foxfire Process}

A set of instructional procedures has evolved to guide implementation of the Foxfire approach. This process incorporates the core practices into a sequential series of steps that guide the teacher and students in meeting state and local objectives established for a given area of study (Wigginton, in press). The process is quite different from the traditional approach in which the teacher generates the lesson plan, activities, resources, and procedures for evaluating the outcome of instruction. In the Foxfire process students and teacher together negotiate a topic of study, select a project to complete related to the topic, plan the steps to achieve the project, identify the instructional objectives that the project can meet, and document how they will demonstrate that they have achieved the objectives through activities in the project. Table 1 gives an overview of how a teacher might cover objectives of learning spelling words using the Foxfire model, compared to traditional teacher-centered approaches

Although the procedures used in the Foxfire methodology seem to be very different from the traditional orientation of programs for students with a learning disability, the procedures actually incorporate effective instruction practices advocated by special educators. For example, the Research To Practice: Lesson Structure procedures distributed by the ERIC Clearinghouse on Handicapped and Gifted Children (1987) reads like a Foxfire manual. Teachers of students with mild disabilities are advised to gain the learner's attention (Foxfire steps 1-8), review relevant past learning (Foxfire steps 1, 2, and 4), communicate the goals of the lesson (Foxfire steps 3 and 7), model a skill to be learned and prompt for correct responses (Foxfire steps 6 and 7), check for mastery (Foxfire steps 3 and 7), and close the lesson (Foxfire step 8). Foxfire differs from traditional approaches because it packages learning into a holistic, student-centered approach, rather than into a teacher-centered focus on isolated skill deficits.

\section{Steps 1 and 2: Characteristics of the Good Teacher and Memorable Experiences}

In the Foxfire approach the first two steps entail having the students identify the characteristics of the good teacher and the charac-
STEPS TO IMPLEMENTATION OF THE FOXFIRE APPROACH

(Wigginton, Foxfire course lecture, September 27, 1989).

Step 1 Students identify characteristics of the GOOD TEACHER.

Step 2 Students identify MEMORABLE EXPERIENCES and what characterize these experiences.

Step 3 Teacher reviews the ACADEMIC AGENDA. We need to deal with this and set the expectation that this is why we are doing what we are doing, and what we are to learn from the experience. These objectives are nonnegotiable.

PRETEST on content, skills, and attitudes.

Step 4 Teacher asks: Where do you see this? Why is it important? This makes the REAL-WORLD CONNECTION. The students are to bring the need to the level of consciousness.

Step 5 Students SELECT A PROJECT that will incorporate the Where? Why? (Step 4) and objectives from the Academic Agenda (Step 3).

Step 6 Students DEVELOP THE PLAN. Who is it for? What value will the project be and for whom is it being developed? What will the project do for others?

Step 7 Students refer back to the Academic Agenda to see which OBJECTIVES will be incorporated in project.

EVALUATION: How will you (the student) prove to me (the teacher) that you are achieving the objective? (e.g., by taking a chunk of this project and getting it published).

Step 8 Teacher provides opportunities for students to REFLECT and EXTEND. What's Next? So what? We need to review the skills, understandings we have. How are we doing in terms of the specified objectives (Academic Agenda)? How can we choose something else that uses the skills we have to do something different, more intriguing, more elegant?

From Eliot Wigginton, Foxfire course lecture, September 27, 1989

teristics of memorable experiences based on their previous school experiences. These two steps provide the teacher and student with sets of markers to be used in evaluating what the students and teacher can do together to make the planned learning experiences another memorable experience in their lives.

The Good Teacher and Memorable Experience exercises are done as two separate activities in groups small enough to give each student ample opportunity for individual input. Students are asked to list what they perceive as the characteristics of a "good teacher," and a student recorder (or teacher, if necessary) records their observations. If there are multiple groups, each recorder identifies the characteristics discussed by his or her group. These characteristics are printed on a chart for later reference by the whole class. 
TABLE 1

\section{Comparison of Traditional and Student-Directed Spelling Lesson}

\section{Traditional Approach}

The teacher says: "Our next spelling lession is Lesson 12 on page 49 . Open your books and turn to the first activity in Lesson 12."

The teacher has each student use the trace, copy, cover, write, and check method to practice the 15 words in Lesson 12.

Each day the teacher assigns students another activity to use in memorizing the words (e.g., teacher uses the computer to produce crossword puzzles for students, assigns them to write the words in sentences, and gives them pre- and posttests).

On Friday students take their spelling test and go on to the next lesson regardless of their performance.

\section{Foxfire Approach}

The teacher says: "You have decided to write a letter to your parents to invite them to see your play. What do we need to be able to do to write a letter to them?" The students discuss the elements of a letter with the teacher, who lists the skills on chart paper. One of the skills the students note is "spelling the words right." The teacher asks: "How will we decide which words to learn?"

After writing a first draft of the letter, the students, with the teacher's help, identify high-frequency words that are misspelled. The class decides on a common spelling list of four high-frequency words that would benefit everyone. Each student adds four words unique to his/her list.

The teacher asks: "What is the best way to learn these words?" Again, teacher and students discuss ways to help memorize words. They decide that copying spelling words isn't helpful but that two students working together could use their classroom computer and software to develop a crossword puzzle for the common words. Other students decide to play Hangman. The students vote to accept the teacher's suggestion of writing the words in sentences.

The students write a letter of invitation to their parents during which they spell their words from memory. The teacher assigns a spelling grade based on the percentage of target words spelled correctly.
The students' Good Teacher list provides their teacher with a connection to the teacher qualities the students admire and appreciate. This list further serves as an excellent starting point to develop a checklist for the teacher to refer to evaluate his or her effectiveness.

Different groups of students show little variation in the teacher characteristics they identify (Wigginton, 1989). Students typically indicate they want a teacher who cares about them as individuals, can be trusted, has a sense of humor, is fair, makes learning fun, and is willing to help students when they need assistance.
Good teachers:

-never embarrass their students in class.

- know their subject well.

-are excited about their subject.

-love to teach.

- treat student work seriously.

-are fair. They give you a second chance.

—don't have favorite students or pets. (p. 10)

The characteristic of trust, in particular, seems to be critical in 
fostering self-determination among mildly disabled students (Adelman \& Taylor, 1986; Deci \& Chandler, 1986), for as Poplin (1988a) notes, "Few of us learn from those whom we distrust" (p. 409). When students trust the person who guides their learning, they are free to respond, make decisions, and act upon the learning experience with confidence.

The identification of memorable experiences is a component of the Foxfire approach that develops a linkage to those moments when the experience of learning was unforgettable. The focus of this activity is to extract the components of experience that made it memorable rather than to recall specific content or skills. A sophomore in a program for students with learning disabilities systematically reviewed his 10 years of schooling by naming each teacher without recalling any moments that were memorable. He then said, "Kindergarten was the most memorable, because we got to play, eat, and take a nap" (Ensminger, 1991).

This activity typically is carried out in small groups to maximize individual participation. After students have listed memorable experiences, they decide what it was about each experience that made it memorable, why it was special. Often students' experiences are memorable because they involved the opportunity to make something or see the real thing (e.g., "We made paper from wood pulp right in our classroom"), a chance to work cooperatively with classmates (e.g., "I remember how my friends and I drew a mural about dinosaurs in fourth grade), being able to share their work with others, an audience (e.g., "We sent our letters to the soldiers in Saudi Arabia, and they wrote back"), a chance to make decisions about how they did a project (e.g., "We planned the whole menu of what we were going to eat"), and an opportunity to accept responsibility (e.g., "We called police headquarters ourselves and asked if a detective would speak to our class").

The components that made for memorable learning experiences are listed on another chart as the students name them, and this list becomes another set of markers that are referred to as the learning experience progresses. The Memorable Experiences list serves as a reminder to students of components that have fostered learning in the past, and it promotes including these experiences in future learning. Through identifying students' memorable learning experiences, the teacher gains insight into the students' learning history. Identifying students' "shining moments" also gives teachers insight into how to individualize instruction and engage students in processes that match their individual learning style - taking advantage of possible student strengths such as learning from direct experiences or collaborating with others.

\section{Step 3: The Academic Agenda}

The third step in implementing the Foxfire approach is to review the objectives (the Academic Agenda) students are to achieve. This step sets the expectation for why the students are in this class and what is to be learned from the experiences they plan. The academic agenda may include the curriculum objectives mandated by state or local guidelines, the objectives for the special program to which the student is assigned, or the IEP objectives for each student. Whatever objectives have been specified, these become nonnegotiable requirements. But the students and teacher negotiate on how the objectives are to be achieved. Presentation of the academic agenda is a new experience for many students as they often are unaware that curriculum objectives exist or that IEP objectives have been developed for them. These objectives should be posted on another chart, and as students begin to develop their learning experiences, the objectives are reviewed to identify those that will be achieved by the experience.

To get an idea of students' level of performance on these objectives, each student's present level of functioning should be established using informal classroom-based procedures (e.g., pretests, work samples, and observations of performance in areas outlined by objectives). Information about the present level of performance may include an evaluation of student attitudes as well as content and skill mastery levels, as shown in Figure 1. These results are made available to the students, and they serve as a baseline for students to evaluate their progress through the learning experience.

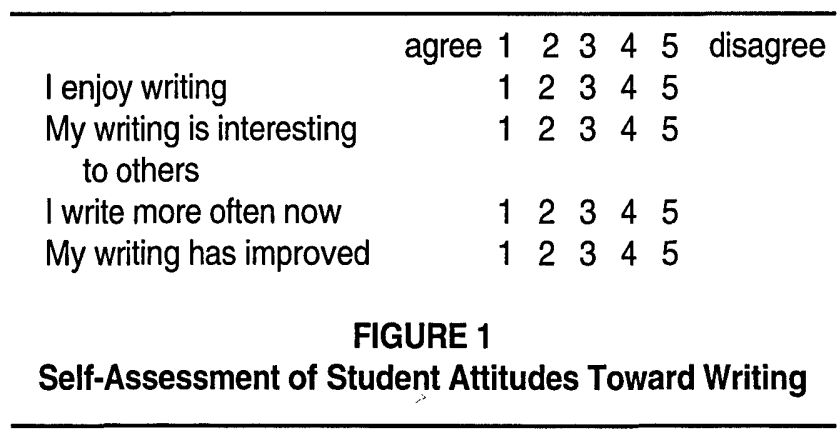

\section{Step 4 Real-World Connections}

To further assist students in making a real-world connection with the academic agenda, they are asked to identify instances from their experience in which they have seen the skill or content that is specified in the objective. The students should be guided to identify why this specific skill or knowledge is important. This is the phase of the implementation process that makes the objectives meaningful and purposeful and thus provides a connection between the academic agenda and the student's prior knowledge. As students identify where they have seen the objectives in real-life and why the objectives are important, these observations are recorded as a source of ideas to be used to generate projects that would address the objectives of the Academic Agenda. As in previous steps, the information the students provide should be placed on chart paper or overhead transparencies for later reference, as in Figure 2. 


\section{Objective: Use descriptive words and elaborative language}

\section{Where is this found?}

\author{
Commercials use descriptive words, like a juicy \\ hamburger
}

\section{Talking about an exciting football game}
Trying to convince your mother that a teacher was unfair
Telling about a movie or video that you liked—or the name of a movie

Making a story more interesting

Writing a good song

When you're trying to be interesting

Sometimes headlines in the newspaper

\section{FIGURE 2}

\section{Connecting Objectives to the Real World}

\section{Step 5: Choosing a Project}

After makimg the connections with previous memorable learning experiences and the learning objectives that must be achieved, the students identify the project on which they will work. Starting with the ideas generated when linking their objectives to the realworld examples of those objectives (Step 4), the students and the teacher brainstorm possible topics and projects of interest. As in previous steps, individual student contributions are valued and recorded as potential topics or projects to be explored. As in all aspects of the process, the teacher may contribute his or her ideas as well.

This part of the process usually takes some time because the class should explore all possibilities, and each student's contributions should be respectfully considered. Following the enumeration of possibilities, the students discuss the value of the proposed projects, who will be the recipients of the developed project and what it will do for them, and how it captures the elements from the memorable moments list. The students progressively narrow the possible list until one project or topic receives a majority vote.

For example, a teacher of a cross-categorical special education resource class in Georgia, in her first application of the Foxfire approach, told her fourth and fifth grade students that they could study anything of interest to them if they would agree on one topic and then read and write about it. The students suggested the following topics:

\author{
How to get rich \\ Rockdale County history and people \\ How to write on the chalkboard \\ How to be a professional skateboarder \\ How to be a model \\ How to build a house. (Jones, 1988, p. 29)
}

The students selected the topic "How to build a house."

\section{Step 6: Planning the Project}

Having selected a tentative topic for the project, students develop a plan for their project. They decide what has to be done, what steps are involved in doing the project, and who will do it. Just as important, they discuss the value of doing the project, identify what impact it will have, and consider what it might do for others. At this point, the final nature of the project remains undefined as students explore the components of what they need to do.

After Ms. Jones' class decided to do a project on "How to Build a House," they listed all the people associated with building a house (Jones, 1988). After generating a long list of people and careers associated with house building, one of her students noted that there were too many people to study and not enough time to do it (approximately 5 weeks remained in the school year). The class took another vote and decided to focus on how to design a house and develop blueprints. Ms. Jones told the students that if they wanted an architect to come to the class, they would have to make the arrangements. They identified a local architect and chose a student to call him. The students were unsure about what they should ask the architect, which led to a session on developing questions to ask the architect. Armed with the classmates' questions, the designated student made the call. The architect agreed to come but indicated that certain supplies would be needed and suggested that the students also contact a firm that could make the blueprints.

With that information, another student called a local supply company to get the cost of the materials the architect specified. A third student called a blueprint company to find out the cost to have the blueprints made. After the costs had been identified, the students wrote a proposal to the Foxfire Fund. In the letter the students specified the purpose of the project, the state, local, and IEP objectives to be achieved by the project, and a budget identifying the materials they needed to purchase (about $\$ 50$ ). When the funds were received, another student was designated to serve as the bookkeeper and keep track of what was spent. Ultimately, the students learned about designing homes from the architect, and each student had the opportunity to see his or her design made into a blueprint.

As students plan the project, they identify skills and knowledge they might need and determine how to learn them, identify various resources available to them, create teams with responsibilities to complete specific tasks, plan activities, and set deadlines. Often a project requires getting special permission from the school adminis- 
tration. Students, with the teacher's guidance and support, develop and present their reasons why they should receive special permission for their project.

\section{Step 7: Doing the Project}

Along with planning the project (Step 6), the students and teacher refer back to the Academic Agenda (Step 3) and identify which objectives are incorporated into the project. The objectives identified by Ms. Jones' students to be achieved by their project were:

U Use descriptive words and elaborative language.

- Spell accurately using a dictionary and other spelling aids.

Write a simple paragraph and identify the main idea and summarize the story.

$\checkmark$ Write creatively.

a Participate in the writing process: prewriting, writing, editing, and publishing. (Jones, 1988, p. 29)

The students achieved many more objectives than those listed above, such as telephone skills, socially appropriate interaction, confidence in speaking to adults, new vocabulary, and practical math applications. Ms. Jones also noted that the students gained in self-esteem, effective peer teaching, and interaction.

In this example, students engaged in interesting activities and were in control of planning and coordinating the elements that went into their learning experience. The students never complained about the writing they were doing or objected to the assignments (the phone calls, the proposal for the project, and so on) (Jones, 1988).

Whenever students take ownership of what they are learning, they can frequently identify skills and content they need to learn (e.g., how to introduce themselves properly on the telephone and the types of questions to ask when making a "cold" phone call). The teacher becomes a valued collaborator in helping students develop the needed content and skills. The teacher may teach mini-lessons, direct students to other authorities, or suggest other resources available in the school and community. Textbooks are employed as resources that provide desired information rather than as the curriculum to be followed obediently.

Students and the teacher also decide how mastery of the objectives is to be demonstrated within the project. Here many opportunities are available to individualize for students with disabilities. Students might keep portfolios of their daily written work (e.g., team notes, letters to parents, calculations of expenses or measurements, drawings, and so forth). Much of the documentation of skills may be in the form of pictures, audiotapes of interviews, or videotaping, all done by the students. A checklist of skills the students develop with the teacher's help is often useful (e.g., Steps in the writing process include ...), and peer review of work offers additional corrective feedback.
The final reports of their study of the design and development of blueprints written by Ms. Jones' students, along with their individual blueprints, were displayed in the front hall of the school near the office. This allowed other students and teachers to become an audience for their work and gave students an opportunity for others to appreciate what they had learned from this experience.

The students were engaged in a meaningful experience that permitted them to see a connection between what they were required to learn, but the experience was so rich that the students were not only achieving their objectives, but they were also going beyond them. Through the various assigned activities, the writing of letters, the negotiation with the architect and the blueprint company, and the final writing of the experience of designing and developing blueprints for a house, these students demonstrated that they had mastered their objectives. Because the students were able to specify the objectives achieved and how they knew they had achieved these objectives, the objectives became a meaningful and purposeful part of the experience.

\section{Step 8: Reflecting and Extending}

To provide multiple opportunities for students to reflect on what is being accomplished and what new skills are being acquired, students are asked throughout the project to think about their progress and if what they are doing reflects their memorable moments and achieves their academic agenda. Upon completing the project, Wigginton (personal communication, September 27, 1989) expresses the question that highlights the next step: "How can we choose something else that uses the skills we have (that will permit us) to do something different, more intriguing, more elegant?" That question leads to a recycling of the steps as students once again review their Academic Agenda and proceed to select a new topic and project that spirals gracefully out of their previous project.

A group of ten 7-year-old students with learning disabilities decided to master their objective on "matching rhyming words" by making holiday cards (Rice, 1991). As they reflected on their holiday card project and learning objective, the students decided to include listening to and copying lines from poems as part of their work on rhyming words. They soon were able to differentiate the styles of Shel Silverstein, Langston Hughes, and Robert Frost.

Even with their preparation, Rice reports that their initial efforts at writing were often disappointing: "Hope you're not sneezin' This holiday season." Although the verses did rhyme, the teacher repeatedly had to ask students to reflect on the purpose of writing a holiday card and the type of message they wished to send during the holidays. As a natural extension of their work, the students decided to sell their cards, and with the profits they purchased some of the necessities, such as mittens and school supplies, needed by children at a local shelter for the homeless. 


\section{IMPLICATIONS FOR TEACHER EDUCATION IN SPECIAL EDUCATION}

Preparation for teachers of students with mild disabilities who wish to employ these procedures in a holistic, intrinsically motivating approach should include an orientation of:

- changing the instructional focus from correcting deficits to that of enhancing learners' abilities.

— viewing learners more holistically as individuals with knowledge, experience, interests, and desires.

- moving away from the textbook and worksheet as the major media of instruction to the use of natural, real-world tasks.

-recognizing that curriculum objectives should be taught as they relate to the student experience rather than taught in isolation.

- promoting self-determination by collaborating with students in the decision-making process, thus relinquishing teacher control of instruction.

- viewing evaluation as something that goes on continuously in the learning act rather than as a measure obtained on a teachermade or standardized test.

The deficit model of instruction that has guided the field of special education for the past three decades has promoted fragmented learning and dependence. Research rarely centers on what students with mild disabilities do well. The instructional approaches generally have been aimed at "fixing" the identified deficit. Eligibility reports and IEPs focus primarily on information about what students cannot do. Our direction of thought must be changed from looking for deficits to thoughts of what strengths and interests the student has and capitalizing on what the student $c a n d o$.

Teachers must be guided to understand the importance of experience and to become familiar with students' past experiences as well as present interests in the world around them. Teachers must become acquainted with the students' culture and family life and fully assess each student's present home and community activities, what the student watches on television, what activities he or she engages in with family and friends, what he or she likes to eat, and so forth. Only through a full awareness of the student's knowledge, experience, interest, and desires can teachers form a clearer understanding of what life means to the individual learner.

And life, as Whitehead (cited in Sizer, 1984) has indicated, is the only subject matter of education. The use of life experiences is what gives meaning to all that is taught, for if instruction has no meaning, no application, it is useless because it has no foundation, no building base to which the information can be attached. Instruction dominated by textbooks and worksheets makes limited connections to students' lives and experiences. Because most of the students placed in special education have not succeeded previously in the textbook orientation of the regular classroom, they typically have developed a negative image of this media for learning. The opportunity to delve into a topic of current interest to students can provide the essential content from which curriculum objectives can be achieved. The textbook certainly may serve as a reference for students and teachers, but it should not dominate the plan of instruction.

The curriculum and IEP objectives should be integrated into the instructional experiences planned by the students and teacher. By viewing objectives as components of holistic experiences, the instructional task becomes one of guiding students to recognize the essential objectives as they engage in the planned experience. To spend inordinate amounts of time teaching objectives merely for the purpose of passing a test is patently unfair to students, yet this is a frequent practice in many secondary special education programs. Objectives that are taught in isolation from familiar content and have not been practiced in some real-life experience of the student is meaningless information-never mastered, soon to be forgotten.

Student motivation is a key ingredient in the learning process. Motivation should be inspired by interest and desire, not imposed or manipulated by extrinsic schemes. Students need to be provided the opportunity to assume responsibility and to take control of planning how they will achieve the academic agenda specified, whether it be from a state or local curriculum guide or their own IEP. Learning to allow students a role in the planning process will require teachers to be trained in collaborative, cooperative learning procedures. The case studies teachers report in various issues of Hands-On: A Journal for Teachers frequently mention the difficulty they have in letting go of control. The teacher models we have had and the pressure to maintain quiet, orderly classrooms have done much to promote teacher-dominated classrooms. Langston (1991), a teacher of students with behavior disorders, eloquently expressed her fear of chaos before implementing a Foxfire experience in her classroom. She soon discovered that her fears were ill founded when students are given the opportunity to establish rules of behavior and the responsibility for implementing them.

Teachers not only need training in the process of collaboration with students, but they also need peer and administrative support. The Foxfire Teacher Outreach Center, through the local networks, provides a support system that keeps teachers in contact with each other to share positive experiences and to learn from negative instances as well.

Evaluation of learning is an essential component of life. Teachers will need to become more flexible and creative in identifying ways students can demonstrate their accomplishments in learning. Each of us, as well as our students, must have some measure of growth and improvement in what we know and are able to do. Appraisal of new knowledge, skills, strategies, or attitudes cannot be obtained readily by paper-and-pencil tests. Procedures for documenting student performance must be more than some end-of-unit 
or standardized measure that focuses more on the product of performance. Students need to be involved in identifying ways they will be able to demonstrate that they have achieved specified curriculum objectives. This involvement should include the opportunity to design procedures for evaluation, record results, and report their progress through dialogue with the teacher and significant others. A portfolio with samples of student work, journal entries, and verbal self-descriptions of what they now know that they didn't know before can be used as a method of documentation. Students can be provided checklists with a place to note progress toward meeting specific objectives. Important to the holistic, experiential approach is to have students involved in evaluating what they do, to judge how well they are doing and to identify the targets for selfimprovement.

In implementing the experiential approach, teachers should start out small by selecting a single subject or content area (e.g., reading, math, science, social studies) and following the procedures during that one period of the day. Perhaps the most intriguing aspects of observing teachers before and after they have been exposed to the Foxfire pedagogy is that they become energized as much as the students. In conversations with Foxfire-trained teachers (including special education teachers), they are constantly surprised at their students' capability to plan and carry out the development of projects, amazed at how few behavior problems occur, and are revitalized about teaching. Teachers, too, become bored with the standard textbook approach to instruction.

\section{SUMMARY}

An experiential, holistic approach to instruction that embraces students as partners in the learning process has much to offer. The Foxfire approach is one way of making learning more meaningful for students and teachers. The Foxfire approach incorporates many practices that meet the unique needs of students who have academic learning difficulties. The approach emphasizes the importance of connecting learning to student knowledge and experience. It incorporates opportunities for students to focus on content that is of interest to them and to plan for the development of a project that will be of value to themselves or others. It fosters social development through group interaction and models the democratic process of group decision making. Motivation is enhanced by the value of the student-selected content and the opportunity to make decisions about how the work will be accomplished (self-determination). In documenting the achievement of curriculum objectives, the student is constantly aware of progress as well as areas in need of improvement. The student takes ownership for what he or she learns and the process for learning.

The change in orientation from a textbook, isolated objective, instructional approach to one that emphasizes student-directed, holis- tic learning will require changes in teacher orientation. Support will have to be provided through training programs and peer networks if teachers are to gain the confidence to venture into an experiential approach, such as Foxfire.

\section{REFERENCES}

Adelman, H. S., \& Taylor, L. (1986). An introduction to leaming disabilities. Glenview, IL: Scott, Foresman \& Co.

Adelman, H. S., \& Taylor, L. (1990). Intrinsic motivation and school misbehavior: Some intervention implications. Journal of Learning Disabilities, 23, 541-550.

Affleck, J. Q., Edgar, E., Levine, P., \& Kortering, L. (1990). Postschool status of students classified as mildly mentally retarded, learning disabled, or nonhandicapped: Does it get better with time? Education \& Training in Mental Retardation, 25, 315-324.

Cegelka, P. T. \& Prehm, H. J. (1982). Mental retardation: From categories to people. Columbus, $\mathrm{OH}$ : Charles E. Merrill.

Cohen, M. W. (1986). Intrinsic motivation in the special education classroom. Journal of Learning Disabilities, 19, 258-261.

Clough, P. (1988). Bridging "mainstream" and "special" education: A curriculum problem. Joumal of Curriculum Studies, 20, 327-338.

Deci, E. L., \& Chandler, C. L. (1986). The importance of motivation for the future of the LD field. Journal of Learning Disabilities, 19, 587-594.

Dewey, J. (1963). Experience and education. New York: Collier.

Edgar, E. (1987). Secondary programs in special education: Are many of them justifiable? Exceptional Children, 53, 555-561.

Ensminger, G. (1991). Deframenting fragmented learners. Hands-On: A Journal for Teachers, 39, 44-48.

ERIC Clearinghouse on Handicapped and Gifted Children. (1987). Research to practice: Lesson structure (ERIC Digest No. 448). Reston, VA: Council for Exceptional Children.

Featherstone, W. B. (1951). Teaching the slow learner (rev.) New York: Columbia University, Teachers College, Bureau of Publications.

Goodlad, J. I. (1984). A place called school: Prospects for the future. New York: McGraw-Hill Book Co.

Halpern, A. S., \& Benz, M. R. (1987). A statewide examination of secondary special education for students with mild disabilities: Implications for the high school curriculum. Exceptional Children, 54(2), 122-129.

Hasazi, S. B., Gordon, L. R., \& Roe, C. A. (1985). Factors associated with the employment status of handicapped youth exiting high school from 1979 to 1983. Exceptional Children, 51(6), 455-469.

Hasazi, S. B., Gordon, L. R., Roe, C. A., Hull, M., Finck, K., \& Salembier, G. (1985). A statewide follow-up on the post high school employment and residential status of students labeled "mentally retarded." Education \& Training of the Mentally Retarded, 20, 222-234.

Hilke, E. V. (1990). Cooperative learning (Fastback 299). Bloomington, IN: Phi Delta Kappa Educational Foundation.

Ingram, C. P. (1935). Education of the slow-learning child. New York: Ronald Press.

Jones, S. (1988, Summer). Fourth and fifth graders make blueprints from scratch. Hands-On: A Journal for Teachers, 32, 28-32.

Jones, S. (1991, Spring). You're over achieving, honey. . . Hands- On: A Journal for Teachers, 39, 49-54.

Johnson, R. T., \& Johnson, D. W. (1983). Effects of cooperative, competitive, and individualistic learning experiences on social development. Exceptional Children, 49, 323-329.

Kirk, S. A., \& Johnson, G. O. (1951). Educating the retarded child. Cambridge, MA: Houghton Mifflin/Riverside Press.

Langston, S. (1991, Spring). The fear of utter chaos . . in a student-centered classroom. Hands-On: A Journal for Teachers, 39, 20-23.

Lloyd, J. W., Crowley, E. P., Kohler, F. W., \& Strain, P. S. (1988). Redefining the applied research agenda: Cooperative learning, prereferral, teacher consultation, and peer-modulated interventions. Joumal of Learning Disabilities, 21, 43-52. 
McGill-Franzen, A., \& Allington, R. L. (1991). The gridlock of low reading achievement: Perspectives on practice and policy. Remedial \& Special Education, 12(3), 20-30.

Meyen, E. L. (1981). Developing instructional units: For the regular and special education teacher (3rd ed.) Dubuque, IA: Wm. C. Brown Co.

Millward, A. J. (1987). Old wine in discredited bottles? Curriculum development for the low attainer. Oxford Review of Education, 13, 297-306.

Polloway, E. A., Patton J. R., Epstein, M. H., \& Smith, T. E. C. (1989). Comprehensive curriculum for students with mild handicaps. Focus on Exceptional Children, 21(8), 1-12.

Polloway, E. A., Patton, J. R., Smith, J. D., \& Roderique, T. W. (1991). Issues in program design for elementary students with mild retardation: Emphasis on curriculum development. Education \& Training in Mental Retardation, 26, 142-150.

Poplin, M. S. (1984). Summary rationalizations, apologies and farewell: What we don't know about the learning disabled. Learning Disability Quarterly, 7, 130-134.

Poplin, M. S. (1988a). Holistic/constructivist principles of the teaching/learning process: Implications for the field of learning disabilities. Journal of Learning Disabilities, 21, 401-416.

Poplin, M. S. (1988b). The reductionistic fallacy in learning disabilities: Replicating the past by reducing the present. Journal of Learning Disabilities, 21, 389-400.

Reid, D. K. (1988). Teaching the learning disabled: A cognitive developmental approach. Boston: Allyn \& Bacon.

Reid, D. K., \& Stone, C. A. (1991). Why is cognitive instruction effective? Underlying learning mechanisms. Remedial \& Special Education, 12, 8-19.

Rice, E. (1991, Spring). When you're helping the poor, you're never finished. Hands-On: A Journal for Teachers, 39, 27-33.

Sharan, S., \& Hertz-Lazarowitz, R. (1980). A group-investigative method of cooperative learning in the classroom. In S. Sharan, O. Hare, C. Webb, \& R. HertzLazarowitz (eds), Cooperation in education. Provo, UT: Brigham Young University Press.
Sizer, T.R. (1984). Horace's compromise: The dilemma of the American high school. Boston: Houghton Mifflin.

Slavin, R.E. (1990). Cooperative learning: Theory, research, and practice. Englewood Cliffs, NJ: Prentice Hall.

Smith, C. R. (1990). Leaming disabilities: The interaction of learner, task, and setting. Boston: Allyn \& Bacon.

Smith, H. (Ed.). (1989, Fall/Winter). What we have here ... Hands-On: A Joumal for Teachers, 33, 16-80.

Steinberg, Z. (1991). Pandora's children. Beyond Behavior, 2(3), 5-14.

Switzky, H. N., \& Schultz, G. F. (1988). Intrinsic motivation and learning performance: Implications for individual educational programming for learners with mild handicaps. Remedial \& Special Education, 9(4), 7-14.

Torgesen, J. K. (1977). The role of non-specific factors in the task performance of learning disabled children: A theoretical assessment. Joumal of Learning Disabilities, 10, 27-34.

Wigginton, E. (1985). Sometimes a shining moment: The Foxfire experience. Garden City, NY: Anchor Books.

Wigginton, E. (1989). Foxfire grows up. Havard Educational Review, 59, 24-49.

Wigginton, E. (in press). Prologue. In E. Wigginton, (Ed.). Handbook series. Portsmouth, NH: Heinemann, Boynton/Cook.

Wigginton, E. \& Smith, H. (Eds.). (1990, Spring/Summer). The Foxfire approach: Perspectives and core practices. Hands-On: A Journal for Teachers, 35/36, 9-10.

Wolman, C., Bruininks, R., \& Thurlow, M. L. (1989). Dropouts and dropout programs: Implications for special education. Remedial \& Special Education, 10(5), 6-20.

Zigmond, N. (1990). Rethinking secondary school programs for students with learning disabilities. Focus on Exceptional Children, 23(1), 1-22.

Zigmond, N., \& Thornton, H. (1985). Follow-up of postsecondary age learning disabled graduates and dropouts. Leaming Disabilities Research, 1, 50-55.

\section{Appendix}

\section{FOXFIRE TEACHER NETWORK}

\begin{abstract}
Foxfire Teacher
Outreach Center
\end{abstract}

Hilton Smith,

Director of Network
P.O. Box B

Rabun Gap, GA 30568

(404) 746-5318
Bitterroot Teachers' Network

Blue Ridge Teachers' Network
Reva Luvaas-Hess

Barbara Duncan

\section{S-22385 Cave Bay Dr. \\ Worley, ID 83876 \\ (208) 686-1444}

c/o Teacher Outreach

P.O. Box B

Rabun Gap, GA 30568

(404) 746-5319

Division of Graduate Studies

C.N. Box 1860

Carson-Newman College

Jefferson City, TN 37760

(615) 471-3462 
Eastern Kentucky Teachers' Network

Empire State Teachers' Network

Louisville Area Foxfire Network

MountainFire West

Virginia Foxfire

Teacher Outreach Network

Partnership Teachers' Network

Skyline Teachers' Network

SoundFire (Puget Sound

Education Consortium

Foxfire Teachers' Network)
Debbie Bays

Judy Kugelmass

Allan Dittmer

Ann Payne

Marylyn Wentworth

Connie Zimmerman

Bob Jones
P.O. Box 452

Hindman, KY 41822

(606) 785-4858

County Road 143, Box 86 Interlaken, NY 14847

(607) 387-3464

College of Education University of Louisville Louisville, KY 40292 (502) 588-6591

Curriculum \& Instruction 602 Allen Hall West Virginia University Morgantown, WV 26506 (304) 293-4769

R.D. 1, Box 1920

Kennebunkport, ME 04046 (207) 967-0862

285 Lackland Court

Atlanta, GA 30350

(404) 804-8301

9918 NE 144th Lane, \#402 Bothell, WA 98011 (206) 823-1319

\section{PERMISSIONS AND COPYRIGHT}

All rights are reserved. No part of this publication may be reproduced, photocopied, faxed, stored in a retrieval system, or transmitted, in any form or by any means, electronic, mechanical, recording or otherwise, without the prior written permission of the publisher.
Back issues are available for sale. Reproduction requires permission and payment of fees. It is illegal and a violation of Federal copyright law to reproduce this publication without permission. Direct all inquiries to the permissions editor. 